antifreeze, synthetic polyester and resin, etc. Although ethylene glycol is a compound with low toxicity, cases concerning the damage of glycol to central nervous system and respiratory system occur frequently because of its widely use. Long-term exposure under the workplace air with ethylene glycol can lead to coma, heart-failure and even death. The recommended method for the determination of ethylene glycol in the air of workplace ruled in current standard of government (GBZ/T 160.48-2007) has a detection limit of $14 \mathrm{mg} / \mathrm{m}^{3}$. Considering the occupational exposure limit (PC-TWA) of ethylene glycol given by China's Ministry of Health is $20 \mathrm{mg} / \mathrm{m}^{3}$, there is a risk of 'once detection, beyond limit already'. So an improved method with higher sensitivity and lower detection limit should be established to meet the need of practical application.

Methods Ethylene glycol in the air of workplace was collected by solid sorbent tube containing silica gel and desorbed by solvent in the lab. The thus abtained sample was determined by capillary gas chromatography with FID detector. The performance of different kinds of desorption solvent and capillary column was investigated, and the condition of analysis was also optimised. Furthermore, the parameters of the improved method such as detection limit and precision were analysed.

Results As desorption solvent, methanol exhibited best performance with high desorption efficiency and equilibrium speed. And DB-WAXetr is the most suitable capillary column, as ethylene glycol showed stable retention time and sharp peak with good symmetry on it. The regression equation showed a good linear relationship in the range of $0.05-$ $1.0 \mathrm{mg} / \mathrm{mL}$. The detection limit of the method was $0.92 \mathrm{mg} /$ $\mathrm{m}^{3}$ and the precision is $1.5 \%-4.2 \%$.

Conclusion An improved method for the determination of ethylene glycol by capillary gas chromatography was developed. The method is simple, rapid and accurate with wide linear range. Compared with the traditional recommended method, the sensitivity of the novel method was greatly improved with a much lower detection limit of $0.92 \mathrm{mg} / \mathrm{m}^{3}$. The new method is more suitable and reliable for the determination of ethylene glycol in the air of workplace.

\section{INDOOR AIR CONDITIONS OF OFFICE ROOM IN WINTER}

TANAKA Masatoshi. Fukushima Medical University

\subsection{6/oemed-2018-ICOHabstracts.559}

The climate in Japan is generally cool/dry in winter and hot/humid in summer. Winter season is from December to February in Japan. January is the coldest month. We measured indoor air conditions; air temperature, humidity and carbon dioxide (CO2) during 12 months at the office room of one manufacturing industry $(800$ workers). The office hour at this office is from 8:30 to $17: 30$. Average mean value ( \pm standard deviation) of room air temperature in January was $20.3 \pm 3.1^{\circ} \mathrm{C}$, humidity was $32.8 \% \pm 3.5 \%$ and $\mathrm{CO} 2$ was $924.5 \pm 478.2 \mathrm{ppm}$. Average room air temperature at office hour was $24.0 \pm 0.8^{\circ} \mathrm{C}$, maxi/mini air temperatures were $25.1 / 22.2^{\circ} \mathrm{C}$, average humidity was $38.8 \% \pm 2.5 \%$, maxi/mini humidity was $41.3 / 33.7 \%$ and average CO2 was 1350.9 $\pm 228.3 \mathrm{ppm}$, maxi/mini CO2 were $1563 / 792 \mathrm{ppm}$. Setting room air temperature of $25^{\circ} \mathrm{C}$ comprised the highest frequency at air conditioners at this office. Regarding the recommend levels for air conditions in office buildings, air temperature is $17^{\circ} 28^{\circ} \mathrm{C}$, relative humidity is $40 \sim 70 \%$ and CO2 is 1000 ppm during all seasons. As
Conclusion, the room air temperatures at office hour were rather high and humidity levels were low. We recommend setting room air temperature level for energy conservation and health is $17^{\sim} 20^{\circ}$ $\mathrm{C}$, and humidity is about $50 \%$ in winter.

\section{FRAGRANCES/ODOURS IN INDOOR AIR AND HEALTH EFFECTS?}

Peder Wolkoff. National Research Centre for the Working Environment, Lersø Parkallé 105, 2100 Copenhagen, Denmark

\subsection{6/oemed-2018-ICOHabstracts.560}

Introduction On-line interviews of the general population have shown excessive prevalence of health effects stipulated to be caused by inhalation of fragrances, e.g. from consumer products.

Method Four major abundant and common airborne fragrances in indoor air have been reviewed. Their impact on perceived indoor air quality, sensory irritation effects, and sensitisation in the eyes and airways has been assessed. Further, effects on breathing pattern, cardiovascular system, work performance, and the impact in the airways by ozone-initiated fragrance reactions have been reviewed.

Results Maximum reported indoor concentrations of the fragrances are close to their odour thresholds. The concentrations are orders of magnitude lower than their thresholds for sensory irritation. Risk values for long-term effects are also above reported indoor concentrations. Human exposure studies and supported by animal inhalation models do not support sensitisation of the airways at indoor levels. Effects on the breathing rate and mood are inconclusive. Some fragrances may increase the high-frequency heart rate variability, but reduction may occur by aerosol exposure during cleaning activities. Distractive effects that influence the work performance are consistently reported, but their persistence is unknown. There is insufficient information that ozone-initiated reactions with fragrances cause airway effects at indoor levels; contrary, beneficial effects in sensitised animals have been observed.

Discussion Common health effects obtained from on-line interviews are inconsistent with experimental data. In general, lung function and sensory effects are likely due to the 'odour' perception rather than toxic effects of the fragrances. Furthermore, sensitisation by inhalation is not supported by animal studies. The substantial discrepancy between the high prevalence of reported health effects as opposed to lack of experimental support is a continuing challenge; strategies to solve this should be developed, e.g. targeted information about volatile organic compounds and their health effects in indoor air.

\section{EVALUATING AMBIENT AND INDOOR AIR QUALITY OF HOUSEHOLDS IN A METRO MANILA COMMUNITY AFTER A BELOW GROUND PETROLEUM PIPELINE SPILL}

Joselito L Gapas. First Philippines Industrial Corporation, Pasig City, Metro Manila, Philippines

\subsection{6/oemed-2018-ICOHabstracts.561}

Introduction First Philippines Industrial Corporation (FPIC) owns an underground petroleum pipeline bringing refined petroleum products to a depot in MetroManila. In 2010, an 
accidental petroleum leak occurred in an underground section near a residential area. Health risk concerns to residents from petroleum vapour were raised. An environmental site assessment (ESA) done 2011 revealed a cemented layer composed of silty and sand material from 2.0 to 4.5 metres underground, acting as 'vaportard,' limiting upward vapour migration. Impacted groundwater and soil are situated below the vapor-tard, minimising vapour intrusion. As part of the remediation, ambient and indoor vapour intrusion studies have been conducted to determine exposure risks.

Methods Community ambient levels of volatile organic compounds (VOCs) and Benzene have been measured from 2011 to 2015. In 2011, vapour intrusion (VI) study was performed to assess potential indoor air impacts from subsurface vapour intrusion. Probes were installed through concrete floor slabs and sampled for vapours.

Result $99 \%$ of VOCs and $100 \%$ of Benzene ambient air readings are below the detection limit of the photoionization device. $1 \%$ of VOC readings ranged from 0.1 to $2.0 \mathrm{ppm}$. The VI study has detected 17 VOCs in indoor and vapour samples above screening levels. These VOCs in indoor air is not likely to be related to the VI pathway, and linked to background indoor and outdoor sources related to fuel products of combustion such as vehicle traffic from a major highway, asphalt paving, and cooking fuels.

Discussion Results show the 'vaportard,' layer is effective in limiting the upward migration of vapours from the underground release area. Monitored VOCs are from ambient air pollution with mobile sources as major contributor. No risk to health of residents was identified. Remediation is on-going and has achieved the Human Health Risk Assessment targets and is in the final stage of completion.

\section{Industrial Hygiene}

\section{E-WASTE RECYCLING IN CANADA - WORKERS' EXPOSURE TO METALS AND FLAME RETARDANTS}

\footnotetext{
${ }^{1,2} \mathrm{~S} \mathrm{Gravel}^{*},{ }^{2} \mathrm{~B}$ Bakhiyi, ${ }^{3,4}{ }^{4} \mathrm{~S}$ Bernstein, ${ }^{3} \mathrm{ML}$ Diamond, ${ }^{3,4} \mathrm{LM}$ Jantunen, ${ }^{1,2} \mathrm{~J}$ Lavoie, ${ }^{3} \mathrm{~L}$ Ngyuen, ${ }^{1} \mathrm{~B}$ Roberge, ${ }^{2} \mathrm{M}-\mathrm{A}$ Verner, ${ }^{3} \mathrm{C}$ Yang, ${ }^{1,2}$ J Zayed, ${ }^{1,2} \mathrm{~F}$ Labrèche. ${ }^{1}$ Institut de recherche Robert-Sauvé en santé et en sécurité du travail, Montréal, Québec, Canada; ${ }^{2}$ Université de Montréal, Montréal, Québec, Canada; ${ }^{3}$ University of Toronto, Toronto, Ontario, Canada; ${ }^{4}$ Environment and Climate Change Canada, Egbert, Ontario, Canada
}

\subsection{6/oemed-2018-ICOHabstracts.562}

Introduction Electronic waste (E-waste) recycling is a booming industry. E-waste contains metals and flame retardants (FRs) that are released during dismantling processes, thus exposing workers. Several of these substances are associated with adverse health effects. The goal of this study is to assess occupational exposure to metals, brominated (BFR) and organophosphosphate ester (OPE) FRs in e-waste recycling facilities.

Methods Personal air sampling was performed over 8 hour work days with 10 workers in two companies. Analyses covered a dozen metals, BFRs and OPEs, including polybromodiphenyl ethers (PBDEs). Tasks and workstations were described through observation. Metals were analysed by inductively coupled plasma mass spectrometry, and flame retardants by gas chromatography and mass spectrometry. Concentrations below the limit of detection were imputed as $\mathrm{LOD} / \sqrt{ } 2$.

Results The exposure levels for metals were below occupational exposure limits. Geometric means (GM) for air concentration were $918 \mathrm{ng} / \mathrm{m}^{3}$ for copper [range: 487-2200], $346 \mathrm{ng} / \mathrm{m}^{3}$ for lead [121-1000], $85 \mathrm{ng} / \mathrm{m}^{3}$ for cadmium [60240] and one positive sample for yttrium $\left(970 \mathrm{ng} / \mathrm{m}^{3}\right)$. The highest PBDE concentration was for BDE-209 (GM=39 ng/m $\mathrm{m}^{3}$ [6-986]), and the highest OPE was tris (2-chloroethyl) phosphate (TCEP) $\left(\mathrm{GM}=156 \mathrm{ng} / \mathrm{m}^{3}[80-478]\right)$. Lead concentrations were correlated with BDE-153, BDE-183, BDE-209 and tris (1,3-dichloro-2-propyl) phosphate (TDCPP); Spearman's $\rho$ of $0.70,0.89,0.80$ and $0.71(\mathrm{p}<0.05)$, respectively. TDCPP levels were also correlated with BDE-183, copper and cadmium; Spearman's $\rho$ of $0.77,0.84$ and $0.67(\mathrm{p}<0.05)$. Highest levels of BDE-153, BDE-209, TCEP, lead and yttrium were measured at the cathode ray tubes dismantling workstation.

Conclusion These results in E-waste recycling sites clearly show concomitant exposure to various metals and flame retardants, some of which predominate in certain workstations. Upcoming additional samples and their detailed task description will help identify activities and electronic items that may require more attention in e-waste management.

\section{OCCUPATIONAL HYGIENE: STANDARDS AND PRACTICES}

Eoin Collins ${ }^{*}$. Hon. President, Occupational Hygiene Society of Ireland

\subsection{6/oemed-2018-ICOHabstracts.563}

Aim of special session The aim of the session is to show how resources provided through the REACH and CLP Regulations and the revised EN689 standard can be used as tools for assessing and controlling exposure to hazardous substances. The session also aims to share knowledge on the use of biological monitoring for exposure assessment and on how to develop a successful partnership between the fields of industrial hygiene and occupational health. Attendees will hear from experts who have developed standards, guidance and working practices in each of these areas.

${ }^{1}$ Raymond Y Vincent, ${ }^{2}$ Bridget Ginnity, ${ }^{3}$ Kate Jones, ${ }^{4}$ Michel Vangeel

${ }^{1}$ Convenor of the CEN/TC 137 WG1 (Blénod les Pont à Mousson, France)

${ }^{2}$ Ginnity Associates, Ennis, Co. Clare, Ireland

${ }^{3}$ Health and Safety Executive, Buxton, UK

${ }^{4}$ Johnson and Johnson, Antwerp, Belgium

\section{7a EN 689: THE NEW EUROPEAN STANDARD ON TESTING COMPLIANCE WITH OCCUPATIONAL EXPOSURE LIMIT VALUES}

Raymond Y Vincent.

\subsection{6/oemed-2018-ICOHabstracts.564}

(Occupational exposure limit values (OELVs) must not be exceeded over a period of time. The revision of EN 689 gives a strategy for testing compliance with OELVs by measurement of exposure by inhalation to chemical agents. The strategy describes a procedure to perform a small number of exposure measurements to demonstrate with a high degree of confidence that workers are not likely to be exposed to concentrations higher than the OELV, taking into account the variability of exposures.

It comprises three main steps concerning groups of workers having similar exposure (Similar Exposure Group-SEG). 